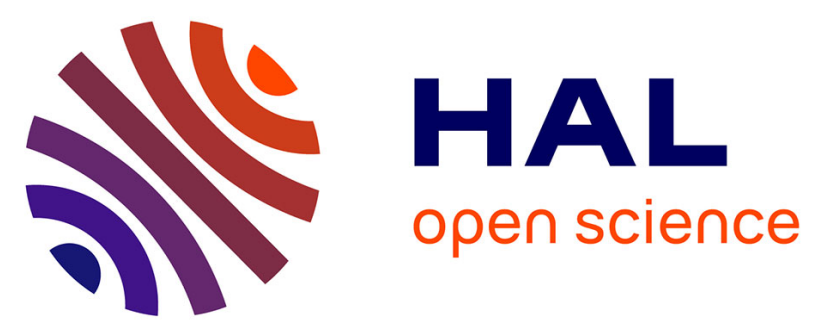

\title{
Monitoring Crystallization Processes in Confined Porous Materials by Dynamic Nuclear Polarization Solid-State Nuclear Magnetic Resonance
}

Marie Juramy, Romain Chèvre, Paolo Cerreia Vioglio, Fabio Ziarelli, Eric Besson, Stéphane Gastaldi, Stéphane Viel, Pierre Thureau, Kenneth D M Harris, Giulia Mollica

\section{To cite this version:}

Marie Juramy, Romain Chèvre, Paolo Cerreia Vioglio, Fabio Ziarelli, Eric Besson, et al.. Monitoring Crystallization Processes in Confined Porous Materials by Dynamic Nuclear Polarization Solid-State Nuclear Magnetic Resonance. Journal of the American Chemical Society, 2021, 143, pp.6095 - 6103. 10.1021/jacs.0c12982 . hal-03345352

\section{HAL Id: hal-03345352 https://hal.science/hal-03345352}

Submitted on 16 Sep 2021

HAL is a multi-disciplinary open access archive for the deposit and dissemination of scientific research documents, whether they are published or not. The documents may come from teaching and research institutions in France or abroad, or from public or private research centers.
L'archive ouverte pluridisciplinaire HAL, est destinée au dépôt et à la diffusion de documents scientifiques de niveau recherche, publiés ou non, émanant des établissements d'enseignement et de recherche français ou étrangers, des laboratoires publics ou privés. 


\section{Monitoring Crystallization Processes in Confined Porous Materials by Dynamic Nuclear Polarization Solid-State Nuclear Magnetic Resonance}

Marie Juramy, Romain Chèvre, Paolo Cerreia Vioglio, Fabio Ziarelli, Eric Besson, Stéphane Gastaldi, Stéphane Viel, Pierre Thureau,* Kenneth D. M. Harris, ${ }^{*}$ and Giulia Mollica*

Cite This: J. Am. Chem. Soc. 2021, 143, 6095-6103

Read Online

ACCESS | Lلll Metrics \& More | 回 Article Recommendations

Supporting Information

ABSTRACT: Establishing mechanistic understanding of crystallization processes at the molecular level is challenging, as it requires both the detection of transient solid phases and monitoring the evolution of both liquid and solid phases as a function of time. Here, we demonstrate the application of dynamic nuclear polarization (DNP) enhanced NMR spectroscopy to study crystallization under nanoscopic confinement, revealing a viable approach to interrogate different stages of crystallization processes. We focus on crystallization of glycine within the nanometric pores $(7-8 \mathrm{~nm})$ of a tailored mesoporous SBA-15 silica material with wall-embedded TEMPO radicals. The results show that the early stages of crystallization, characterized by the transition from the solution

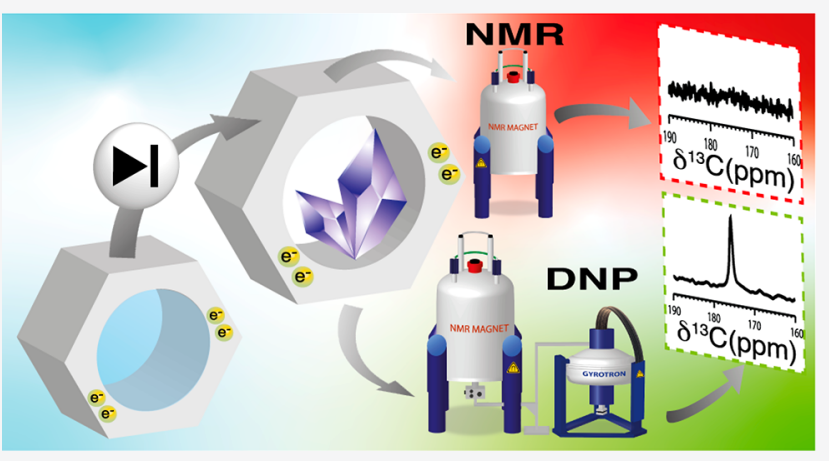
phase to the first crystalline phase, are straightforwardly observed using this experimental strategy. Importantly, the NMR sensitivity enhancement provided by DNP allows the detection of intermediate phases that would not be observable using standard solid-state NMR experiments. Our results also show that the metastable $\beta$ polymorph of glycine, which has only transient existence under bulk crystallization conditions, remains trapped within the pores of the mesoporous SBA-15 silica material for more than 200 days.

\section{INTRODUCTION}

Although crystallization phenomena are central to many processes in chemistry, materials science, and biology (including biomineralization), ${ }^{1-4}$ detailed fundamental understanding of such processes is often difficult to establish. The mechanistic pathway from molecules dispersed in solution to the formation of the "embryonic" crystalline assembly (e.g., the critical nucleation cluster), followed by growth to produce the final crystalline phase, is a complex process, which may be further complicated by the evolution of the system through different transient solid forms such as amorphous phases and/ or metastable polymorphs before the final crystallization product is obtained. ${ }^{5}$ Knowledge of the full mechanistic pathway is critical for advancing our understanding of crystallization processes ${ }^{6,7}$ and is a prerequisite for developing experimental strategies to allow the formation of specific polymorphs to be controlled. ${ }^{8}$

Interestingly, it has been found that crystallization within nanoscale pores can promote the formation and stabilization of polymorphs that are metastable under bulk crystallization conditions. $^{9-13}$ For example, crystallization of glycine within controlled pore glasses (CPGs) or porous polymers (e.g. p-PSPDMA) can "trap" the metastable $\beta$ polymorph indefinitely; $;^{9,14-16}$ in contrast, the $\beta$ polymorph is observed only transiently in crystallization from bulk aqueous solution, transforming rapidly to the more stable $\alpha$ and/or $\gamma$ polymorphs. Furthermore, crystallization in confined media can play a key role in biomineralization processes (e.g., the formation of calcium carbonate and calcium phosphate). ${ }^{17-20}$

Glycine is often used as a model system in polymorphism research, ${ }^{21-34}$ with three polymorphs $(\alpha, \beta, \gamma)$ known to exist at ambient pressure. The thermodynamically stable form is the $\gamma$ polymorph, and the least stable form is the $\beta$ polymorph. Crystallization from water at neutral $\mathrm{pH}$ typically produces the metastable $\alpha$ polymorph (although the $\beta$ polymorph may be formed transiently before the $\alpha$ polymorph). The $\alpha$ polymorph then transforms over time to the stable $\gamma$ polymorph. However, as noted above, crystallization from water in nanoconfined environments may promote the formation of the $\beta$ polymorph. In addition, a dihydrate phase of glycine is also known. ${ }^{24,25}$

Received: December 15, 2020

Published: April 15, 2021 


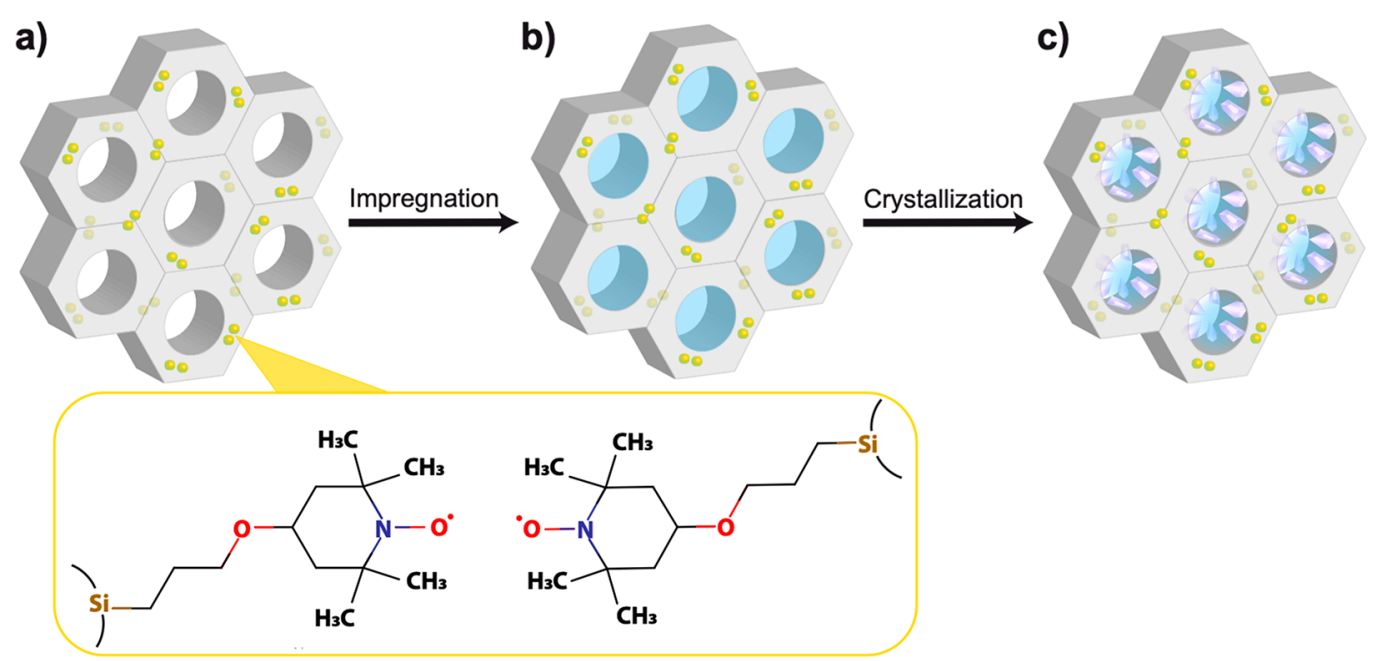

Figure 1. Schematic representation of crystallization of glycine within the pores of mesoporous SBA-15 silica material. (a) Tailored mesoporous silica material containing wall-embedded TEMPO radicals (represented in yellow and defined in the box below). (b) Full impregnation of the pores of the mesoporous silica material with an aqueous solution of glycine (shown in light blue). (c) Evaporation of solvent (water) leads to crystallization of glycine within the pores of the material.

In recent years, in situ NMR spectroscopy ${ }^{35-41}$ has been shown to be a promising strategy for investigating mechanistic aspects of crystallization processes from bulk solution, allowing the simultaneous evolution of both the liquid and solid phases to be probed as a function of time during crystallization. ${ }^{39-41}$ The discriminating accuracy of solid-state NMR chemical shifts allows reliable identification of the solid form(s) (e.g., polymorphs) present at different stages during crystallization. $^{41-44}$ However, as transient solid forms are typically present in very low amounts, short-lived intermediate phases may be undetectable in in situ NMR studies due to the intrinsically low sensitivity of the NMR technique.

In the present work, we exploit dynamic nuclear polarization (DNP) to overcome the inherent problems associated with the low sensitivity of $\mathrm{NMR}^{45-50}$ for monitoring the evolution of crystallization processes, focusing on crystallization in nanoporous environments. In DNP experiments, the sample is irradiated with microwave radiation to transfer the electron spin polarization of unpaired electrons to the nuclear spins, leading to enhancement of the NMR signal strength. However, paramagnetic polarizing agents must be added to the (usually) diamagnetic sample, ${ }^{51-53}$ and the presence of the polarizing agent may potentially change the properties of the system under investigation. In the context of applying DNP experiments to study crystallization, a potential problem is that the polarizing agent may influence the crystallization process. ${ }^{54-56}$ Furthermore, polarizing agents are usually dissolved in certain specific solvents, such as water/glycerol or tetrachloroethane, in order to promote glass formation upon freezing. However, the use of these solvents in crystallization experiments may also modify the outcome of the crystallization process. In the present work, we circumvent these issues by exploiting nanostructured porous materials ${ }^{57-59}$ in which the polarizing agent is incorporated within the pore walls, ${ }^{60,61}$ ensuring (i) that the polarizing agent and the molecules undergoing crystallization are present in different phases and (ii) that the polarizing agent is uniformly distributed throughout the sample as a whole.

We focus on crystallization of $\left[1-{ }^{13} \mathrm{C}\right]$ glycine from aqueous solution within the pores of a mesoporous SBA-15 silica material (pore diameter of approximately 7-8 nm) in which the DNP polarizing agents (TEMPO nitroxide radicals) are embedded in the pore walls. ${ }^{60}$ Our results show that the early stages of crystallization (i.e., the transition from the homogeneous solution phase to the first observable crystalline phase) are readily monitored by DNP solid-state NMR measurements, allowing the existence of metastable solid phases within the porous material to be observed straightforwardly. Significantly, the NMR sensitivity enhancement provided by DNP allows the detection of intermediate solid phases that would not be observable using standard solid-state NMR experiments.

\section{RESULTS}

Figures 1 and 2 describe our DNP NMR strategy to monitor the evolution of crystallization of glycine within the

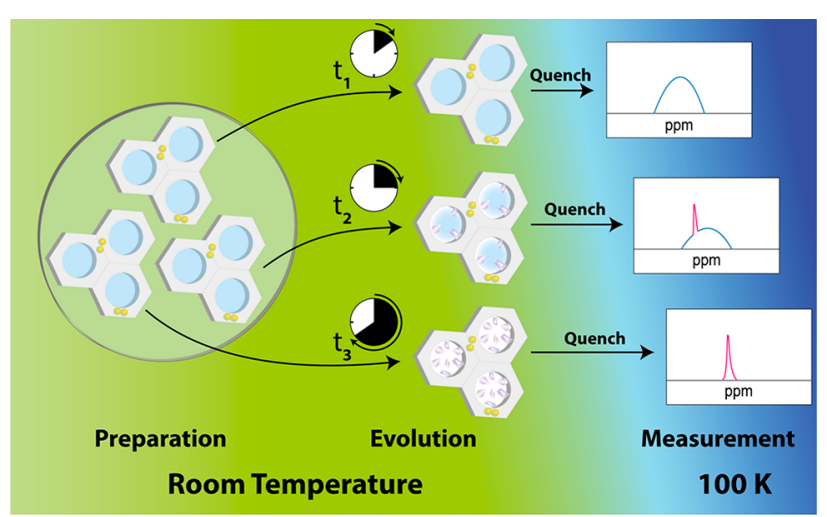

Figure 2. Schematic of the experimental DNP NMR strategy to probe the evolution of crystallization processes.

mesoporous SBA-15 silica material with wall-embedded TEMPO radicals. The mesoporous material is impregnated with an undersaturated aqueous solution of $\left[1-{ }^{13} \mathrm{C}\right]$ glycine (7.7\% w/w; $\sim 1 \mathrm{M})$ at ambient temperature and stored in an open vial which was left open in a desiccator at fixed humidity (43\%), allowing crystallization to proceed within the mesoporous material by solvent evaporation. 


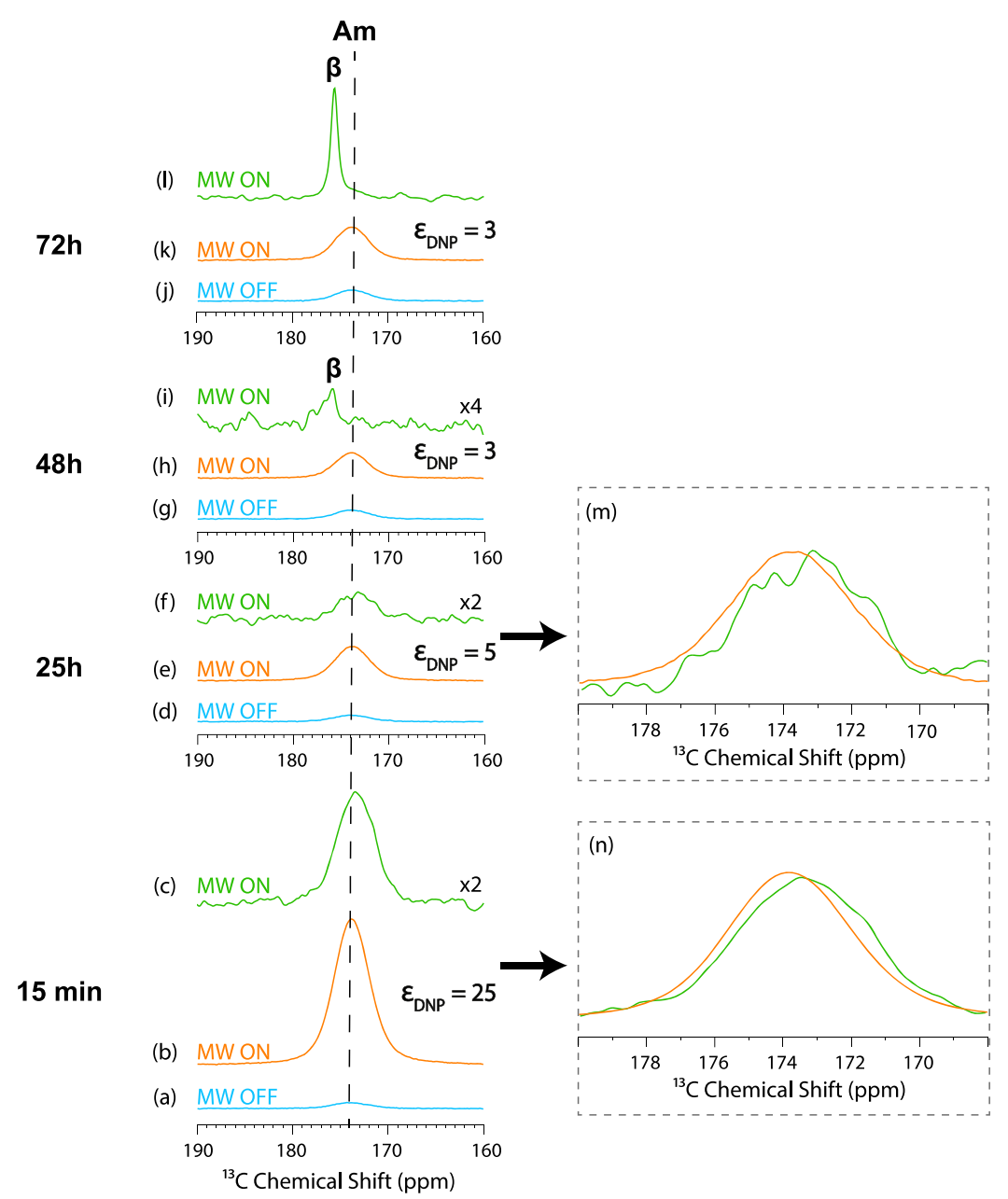

Figure 3. ${ }^{13} \mathrm{C}$ CPMAS (blue and orange) and $T_{1 \rho}$-filtered ${ }^{13} \mathrm{C}$ CPMAS (green) NMR spectra recorded for mesoporous SBA-15 silica materials with wall-embedded TEMPO radicals and impregnated at room temperature with an aqueous solution of $\left[1-{ }^{13} \mathrm{C}\right]$ glycine $(7.7 \% \mathrm{w} / \mathrm{w})$. The samples were quenched after crystallization times of $15 \mathrm{~min}(\mathrm{a}-\mathrm{c}), 25 \mathrm{~h}(\mathrm{~d}-\mathrm{f}), 48 \mathrm{~h}(\mathrm{~g}-\mathrm{i})$, and $72 \mathrm{~h}(\mathrm{j}-\mathrm{l})$. Blue spectra were recorded without microwave irradiation and at $98 \mathrm{~K}$; orange and green spectra were recorded with microwave irradiation and at $110 \mathrm{~K}$ (the difference in temperature is due to the heating effect of the microwave irradiation). Window (n) shows the superposition of spectra (b) and (c). Window (m) shows the superposition of spectra (e) and (f). In (n) and (m), the intensities are scaled to correspond to the same absolute intensity.

At a specific point in time after impregnation, an aliquot of the material is extracted from the vial and transferred to a solid-state NMR rotor. The rotor is then inserted into the DNP solid-state NMR spectrometer at $\sim 100 \mathrm{~K}$, rapidly quenching the crystallization process. No further evolution of the crystallization process occurs, and the so-obtained sample represents the crystallization system frozen in time at the moment of quenching. A range of NMR experiments can then be carried out on the "frozen" crystallization system.

The same procedure is repeated at subsequent time points during the crystallization process. At each value of time, a further aliquot of the impregnated material is rapidly quenched by insertion into the DNP solid-state NMR spectrometer, followed by NMR measurements on the quenched crystallization system. In this way, NMR data are recorded $e x$ situ on the same crystallization system at different values of time, providing individual "snapshots" of the crystallization system and allowing the different phases present as a function of time during the crystallization process to be identified.

Our strategy to investigate the evolution of crystallization of glycine within the mesoporous silica material is demonstrated in Figure 3, which shows DNP-enhanced ${ }^{13} \mathrm{C}$ CPMAS NMR spectra recorded for samples quenched at different times during the crystallization process.

For the sample quenched at $15 \mathrm{~min}$ after impregnation, the ${ }^{13} \mathrm{C}$ CPMAS NMR spectrum (Figure $3 \mathrm{~b}$ ) recorded with microwave irradiation (DNP signal enhancement, $\varepsilon_{\mathrm{DNP}}=25$ ) comprises a broad signal assigned as the amorphous glycine/ water frozen solution observed previously. ${ }^{42}$ Indeed, NMR allows amorphous phases to be distinguished from crystalline phases on the basis of signal line widths, with amorphous phases giving rise to significantly broader lines. The signal from amorphous phases of glycine (including the glycine/water frozen solution) can be suppressed by using a $T_{1 \rho}$ relaxation filter experiment (pulse sequence in Figure 6), which exploits differences in the relaxation times of glycine in amorphous and crystalline phases. ${ }^{62}$

Hence, $T_{1 \rho}$-filtered ${ }^{13} \mathrm{C}$ CPMAS NMR spectra can reveal low-intensity signals from crystalline phases that are hidden under the broad signal due to the amorphous glycine/water frozen solution that dominates the ${ }^{13} \mathrm{C}$ CPMAS NMR spectrum.

For the sample quenched at $15 \mathrm{~min}$, the $T_{1 \rho}$ relaxation filtered ${ }^{13} \mathrm{C}$ CPMAS NMR spectrum (Figure 3c) comprises a 
broad signal that is different from the spectrum of the amorphous glycine/water frozen solution (Figure 3b). The intensity maximum of this broad signal (173.5 ppm) does not correspond to the ${ }^{13} \mathrm{C}$ chemical shift of any crystalline polymorph of glycine in the same temperature region ${ }^{25}(\alpha$ polymorph, $176.8 \mathrm{ppm} ; \beta$ polymorph, $175.5 \mathrm{ppm} ; \gamma$ polymorph, $174.3 \mathrm{ppm}$ ), although it is very close to the ${ }^{13} \mathrm{C}$ chemical shift of crystalline glycine dihydrate ${ }^{25}(173.5 \mathrm{ppm})$. However, the new signal is significantly broader than that observed previously for crystalline glycine dihydrate in bulk crystallization experiments. $^{25}$

To further explore this issue, the standard temperature sequence to generate glycine dihydrate in bulk solution ${ }^{24,25}$ was carried out for the mesoporous silica material after impregnation with an aqueous $\left[1-{ }^{13} \mathrm{C}\right]$ glycine solution $(7.7 \%$ $\mathrm{w} / \mathrm{w})$. However, following this procedure, the ${ }^{13} \mathrm{C}$ NMR spectrum (Figure S1) does not show a sharp signal at 173.5 ppm characteristic of crystalline glycine dihydrate. On this basis, the broad signal at $173.5 \mathrm{ppm}$ in Figure $3 \mathrm{c}, \mathrm{f}$ is unlikely to be due to crystalline glycine dihydrate. Potentially, the broad signal at $173.5 \mathrm{ppm}$ may be due to a phase with higher local concentration of glycine than the amorphous glycine/water frozen solution, perhaps representing clustering of glycine molecules preceding crystallization. This interpretation would be in agreement with previous work in which an amorphous phase was identified in the case of nanocrystals confined in porous glasses. ${ }^{11}$ The phase giving the broad signal at 173.5 ppm is currently under further investigation.

The ${ }^{13} \mathrm{C}$ CPMAS NMR spectrum of the sample quenched at $25 \mathrm{~h}$ also comprises a broad signal assigned as the amorphous glycine/water frozen solution (Figure $3 \mathrm{e} ; \varepsilon_{\mathrm{DNP}}=5$ ). In the $T_{1 \rho}$ filtered ${ }^{13} \mathrm{C}$ CPMAS NMR spectrum, the broad signal due to the unidentified phase of glycine is still observed but with decreased intensity (Figure $3 \mathrm{f}$ ).

For the sample quenched at $48 \mathrm{~h}$, the ${ }^{13} \mathrm{C}$ CPMAS NMR spectra (Figure $3 \mathrm{~g}, \mathrm{~h}$ ) comprise the broad signal due to the amorphous glycine/water frozen solution. However, the $T_{1 \rho^{-}}$ filtered ${ }^{13} \mathrm{C}$ CPMAS NMR spectrum now contains a sharp, low-intensity signal at $175.9 \mathrm{ppm}$, assigned as the $\beta$ polymorph of glycine (Figure 3i). Significantly, the broad signal at 173.5 ppm due to the unidentified phase is not observed at $48 \mathrm{~h}$, consistent with the possible assignment of this phase as a transient intermediate on the crystallization pathway, serving as a noncrystalline precursor to the crystalline $\beta$ polymorph. We note that our proposal (see above) that the broad signal at $173.5 \mathrm{ppm}$ is due to an amorphous phase with higher local concentration of glycine than the amorphous glycine/water frozen solution is based on the premise that an intermediate phase on the pathway between the amorphous glycine/water frozen solution and the crystalline $\beta$ polymorph would reasonably be expected to have a glycine concentration intermediate between that of the amorphous glycine/water frozen solution and that of the $\beta$ polymorph (i.e., pure glycine).

For the sample quenched at $72 \mathrm{~h}$, the signal due to the amorphous glycine/water frozen solution is still observed (Figure $3 \mathrm{k} ; \varepsilon_{\mathrm{DNP}}=3$ ), while the $T_{1 \rho}$-filtered ${ }^{13} \mathrm{C}$ CPMAS NMR spectrum contains only the sharp signal due to the $\beta$ polymorph of glycine (Figure 31), with higher intensity than the sample quenched at $48 \mathrm{~h}$.

Overall, the DNP signal enhancement decreases as crystallization time increases, possibly due to evaporation of water as crystallization proceeds at room temperature (within the impregnated material). For example, the DNP signal enhancements are close to 1 for the three signals in the ${ }^{13} \mathrm{C}$ CPMAS NMR spectrum (Figure 4) recorded 224 days after

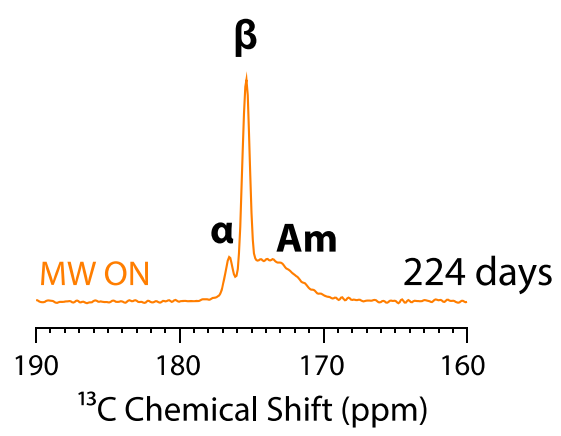

Figure 4. ${ }^{13} \mathrm{C}$ CPMAS NMR spectrum recorded at $100 \mathrm{~K}$ with microwave irradiation for the mesoporous material impregnated with aqueous glycine solution 224 days after impregnation. The signal denoted "Am" is due to the amorphous water/glycine frozen solution. DNP enhancements: $\varepsilon_{\mathrm{DNP}}=1$ for the amorphous phase and $\alpha$ polymorph; $\varepsilon_{\mathrm{DNP}}=1.5$ for the $\beta$ polymorph.

impregnation. The loss of water due to evaporation results in reduced efficiency of the solvent mediated polarization transfer from the polarizing agent (located inside the walls) to the crystalline phases (located inside the pores), which occurs through ${ }^{1} \mathrm{H}-{ }^{1} \mathrm{H}$ spin diffusion. We note that the mass of the sample decreases as a function of time after impregnation, confirming that evaporation of water occurs during the evolution period (Figure S2), although the exact water content cannot be estimated due to periodic removal of the sample for transferring to the NMR rotor.

Importantly, evaporation of water from the crystallization system does not reach completion in our experiments. For a sample left in a sealed desiccator at room temperature and fixed humidity (43\%) for 224 days after impregnation, the ${ }^{13} \mathrm{C}$ CPMAS NMR spectrum (recorded at $100 \mathrm{~K}$; Figure 4) still contains a broad signal due to the amorphous glycine/water frozen solution, together with sharp signals due to the $\alpha$ and $\beta$ polymorphs. Thus, even 224 days after the start of crystallization, the metastable $\beta$ polymorph remains trapped and stabilized within the mesoporous silica material at room temperature, although clearly some of the sample had transformed to the $\alpha$ polymorph. We note that the relative amounts of the different crystalline polymorphs cannot be readily quantified from ${ }^{13} \mathrm{C}$ CPMAS NMR measurements as each polymorph has different relaxation behavior and CPMAS experiments are intrinsically nonquantitative.

\section{DISCUSSION}

Our results demonstrate that different stages of crystallization of glycine are readily resolved using the DNP NMR strategy presented here. In comparison with previous work on crystallization of glycine from bulk solution, ${ }^{30,40,42}$ crystallization of glycine within mesoporous silica allows more detailed insights as the transformations between different solid forms are significantly slower in the nanoconfined system.

For example, transformation of the $\beta$ polymorph to the $\alpha$ polymorph usually starts within a few minutes in bulk aqueous solution, ${ }^{42}$ whereas the $\beta$ polymorph remains present for several days when the crystallization process occurs in the nanoconfined system. In contrast, crystallization from a bulk aqueous solution of glycine (i.e., without mesoporous materials 
nor DNP polarizing agents) yields the $\alpha$ and $\gamma$ polymorphs after 3 days, as evident from the conventional ${ }^{13} \mathrm{C}$ CPMAS NMR spectrum recorded at room temperature (Figure 5a).

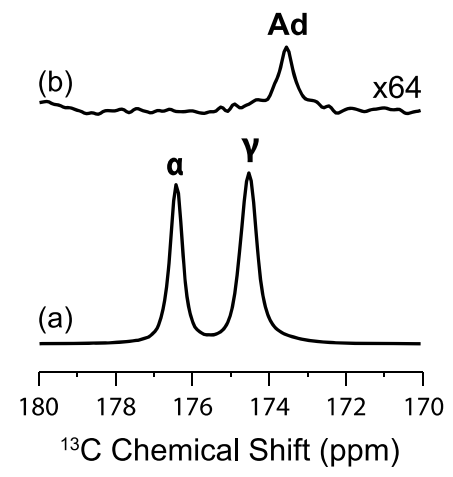

Figure 5. Standard ${ }^{13} \mathrm{C}$ CPMAS NMR spectra recorded (at room temperature and with no polarizing agent present) under the following conditions: (a) solid sample recovered by filtration after 3 days of crystallization in a bulk aqueous solution of $\left[1-{ }^{13} \mathrm{C}\right]$ glycine $(7.7 \% \mathrm{w} / \mathrm{w})$ and (b) 3 days after impregnating nonporous silica with an aqueous solution of $\left[1-{ }^{13} \mathrm{C}\right]$ glycine $(7.7 \% \mathrm{w} / \mathrm{w})$. The signal denoted "Ad" is due to glycine adsorbed on the silica surface. ${ }^{63,64}$

In another control experiment, a (nonporous) powder sample of silica was impregnated with an identical aqueous solution of $\left[1-{ }^{13} \mathrm{C}\right]$ glycine $(7.7 \% \mathrm{w} / \mathrm{w})$. In this case, the only signal in the ${ }^{13} \mathrm{C}$ CPMAS NMR spectrum recorded with no polarizing agent present and at room temperature (Figure $5 \mathrm{~b}$ ) is due to glycine adsorbed on the silica surface, ${ }^{14,63,64}$ with no crystalline phases observed. This result confirms that the preferential formation of the $\beta$ polymorph within the mesoporous silica material is a consequence of nanoconfinement rather than due to interaction of the aqueous solution of glycine with a silica surface.

Moreover, we emphasize that our strategy enables very early stages of the crystallization process to be probed, as a consequence of the sensitivity enhancement of DNP. The absolute sensitivity $S=\operatorname{SNR} \times t^{-1 / 2}$ (where SNR is the signalto-noise ratio and $t$ is the experiment time) is $\sim 15$ times higher in our DNP experiments compared to standard solid-state NMR experiments. As a result, the $\beta$ polymorph is detected in the DNP-enhanced ${ }^{13} \mathrm{C}$ CPMAS NMR spectrum recorded $48 \mathrm{~h}$ after starting the crystallization process (Figure $3 \mathrm{i}$ ). In this experiment, $S=0.12 \mathrm{~min}^{-1 / 2}(\mathrm{SNR}=2.2 ; t=344 \mathrm{~min})$.

In addition, $T_{1} \rho$-filtered ${ }^{13} \mathrm{C}$ CPMAS NMR spectra reveal the presence of an unidentified solid phase of glycine (Figure $3 \mathrm{c})$ prior to the appearance of the $\beta$ polymorph. In this experiment, $S=0.23 \mathrm{~min}^{-1 / 2}(\mathrm{SNR}=4.2 ; t=344 \mathrm{~min})$. Without the sensitivity enhancement of DNP, experiment times greater than 50 days would be required to detect both the unidentified solid phase (Figure 3c) and the $\beta$ polymorph at $48 \mathrm{~h}$ (Figure $3 \mathrm{i}$ ) under the same crystallization conditions. In future studies, DNP NMR sensitivity could probably be improved by the use of different polarizing agents and/or different sample preparation methods, such as the study of crystallization from an aqueous solution containing both AMUPol and the molecule under investigation dispersed homogeneously in a mesoporous material, ${ }^{65}$ although the amount of polarizing agent, in this case, should be kept low to minimize the risk of affecting the crystallization process.

Our results demonstrate that the sensitivity enhancement of DNP opens up the opportunity to detect earlier stages of crystallization processes compared to using standard solid-state NMR methods. Moreover, our results indicate that crystallization processes evolve more slowly in confined porous media than in bulk solution, in agreement with previous studies of crystallization in nanoconfined environments. ${ }^{9,10,66}$ Thus, the experimental strategy presented here has the potential to reveal the existence and possibly determine the structure of new transient phases during crystallization processes, which typically evolve too quickly in bulk solution to allow detection under typical in situ measurement conditions. Furthermore, our strategy is applicable for investigating different crystallizing substances and different solvents, representing a versatile approach for gaining new insights into a broad range of crystallization systems.

\section{EXPERIMENTAL SECTION}

Sample Preparation. Mesoporous Silica. The mesoporous silica material was SBA-15 with wall-embedded TEMPO radicals, synthesized by the method of Besson et al. ${ }^{60}$ (particle size $<10$ $\mu \mathrm{m})$. The mesopores have cylindrical shape (diameter, 7-8 nm) and are connected through micropores. The radical concentration $(0.52 \pm$ $0.03 \mathrm{mmol} / \mathrm{g}$ ) and the uniform distribution of radicals were established by electron paramagnetic resonance. ${ }^{67}$

DNP enhancements $\left(\varepsilon_{\mathrm{DNP}}\right)$ measured on a $0.2 \mathrm{M}$ aqueous solution of $\mathrm{U}-{ }^{13} \mathrm{C} /{ }^{15} \mathrm{~N}$ proline were used to evaluate the radical concentration and homogeneous distribution in the SBA material. Values of $\varepsilon_{\mathrm{DNP}}$ measured for the material used in this study are comparable to those reported previously $^{60}$ for SBA materials with similar radical concentrations.

Crystallization Solutions. $\left[1-{ }^{13} \mathrm{C}\right]$ glycine (99\%) and water with natural isotopic abundances (HPLC grade) were purchased from Sigma-Aldrich. An aqueous solution of $\left[1-{ }^{13} \mathrm{C}\right]$ glycine $(7.7 \% \mathrm{w} / \mathrm{w} \sim 1$ M) was prepared in a glass vial $(2 \mathrm{~mL})$. The solution was stirred at room temperature for $10 \mathrm{~min}$ until dissolution was complete. Then, the solution was passed through a $0.45 \mu \mathrm{m}$ poly(tetrafluoroethylene) syringe filter to remove any insoluble particulate matter.

The amount of solution $(160 \mu \mathrm{L})$ used for impregnation was approximately equal to the total pore volume of the mesoporous material, based on the total mass and specific surface area of the material (determined by the Brunauer-Emmett-Teller (BET) method), while the pore size distribution was calculated from desorption isotherms using the Barrett-Joyner-Halenda (BJH) method. This procedure maximizes the loading of glycine within the pores while minimizing the residual amount of glycine on the exterior surfaces of the mesoporous material. As a result, the amount of glycine added to the mesoporous material $(80 \mathrm{mg})$ was between $5.6 \times 10^{-5}$ and $7.7 \times 10^{-5} \mathrm{~mol}$.

Experimental Protocol for DNP Solid-State NMR Studies of Crystallization. An amount $(160 \mu \mathrm{L})$ of aqueous $\left[1-{ }^{13} \mathrm{C}\right]$ glycine solution $(7.7 \% \mathrm{w} / \mathrm{w})$ was used to impregnate the mesoporous silica material with wall-embedded TEMPO radicals $(80 \mathrm{mg})$. The impregnated material was stored in a glass vial $(2 \mathrm{~mL})$, which was left open in a desiccator at fixed humidity (43\%) and room temperature. Humidity was controlled by a supersaturated aqueous solution of potassium carbonate. For reference, we note that reported values $^{68-70}$ of the concentration of a (bulk) equilibrium saturated aqueous solution of glycine in the vicinity of room temperature are in the range $17.7-19.9 \% \mathrm{w} / \mathrm{w}$ at $\sim 20{ }^{\circ} \mathrm{C}$ and $20.0-22.6 \% \mathrm{w} / \mathrm{w}$ at $\sim 25{ }^{\circ} \mathrm{C}$. The crystallization process was monitored by recording ${ }^{13} \mathrm{C}$ CPMAS NMR spectra on different aliquots $(\sim 15 \mathrm{mg})$ of the impregnated mesoporous silica material extracted at different time points after starting the crystallization process. Each aliquot was packed in a different $3.2 \mathrm{~mm}$ sapphire NMR rotor and rapidly quenched by insertion into the DNP solid-state NMR spectrometer. 
To investigate whether rapid quenching of aqueous glycine solution may trigger crystallization, ${ }^{71}$ an aqueous solution of $\left[1-{ }^{13} \mathrm{C}\right]$ glycine that was under-saturated at ambient temperature $(11.8 \% \mathrm{w} / \mathrm{w} \sim 1.8$ $\mathrm{M})$ was flash cooled to $\sim 100 \mathrm{~K}$ in less than 1 min inside the NMR spectrometer. No signal due to crystalline phases of glycine was observed in the ${ }^{13} \mathrm{C}$ CPMAS and $T_{1 \rho}$ filtered ${ }^{13} \mathrm{C}$ CPMAS NMR spectra. Only a broad signal due to the amorphous glycine/water frozen solution was observed.

The effect of temperature quenching on crystallization was also investigated through a "freeze-thaw" cycle (specifically, cooling to $100 \mathrm{~K}$, warming to room temperature, and then cooling again to 100 $\mathrm{K})$. No changes were observed in the ${ }^{13} \mathrm{C}$ CPMAS NMR spectrum recorded at $100 \mathrm{~K}$ in successive cycles, indicating that there was no transformation of the glycine phase throughout this experiment.

NMR Spectroscopy. DNP Solid-State NMR. All DNP solid-state NMR spectra were recorded on a Bruker $9.4 \mathrm{~T}$ wide-bore magnet (Larmor frequencies: ${ }^{1} \mathrm{H}, 400 \mathrm{MHz} ;{ }^{13} \mathrm{C}, 100 \mathrm{MHz}$ ) operated by an AVANCE-III NMR spectrometer with a Bruker $3.2 \mathrm{~mm}$ DNP lowtemperature double-resonance ${ }^{1} \mathrm{H} /\left\{{ }^{29} \mathrm{Si}-{ }^{13} \mathrm{C}\right\}$ MAS probe, with MAS frequency of $8 \mathrm{kHz}$. Microwave irradiation was applied using a gyrotron connected to the NMR probe (frequency, $263 \mathrm{GHz}$; power, $4 \mathrm{~W}$ ). All measured ${ }^{13} \mathrm{C}$ chemical shifts are referenced against the $\mathrm{COOH}$ resonance for the $\beta$ polymorph of glycine recorded at $100 \mathrm{~K}$, which was set to $175.5 \mathrm{ppm}$. ${ }^{25}$

$T_{1 \rho}$ filtered ${ }^{13} \mathrm{C}$ CPMAS NMR spectra were recorded using a pulse sequence (Figure 6) applying a spinlock (duration $\tau_{\mathrm{sl}}$ ) after the $90^{\circ}$

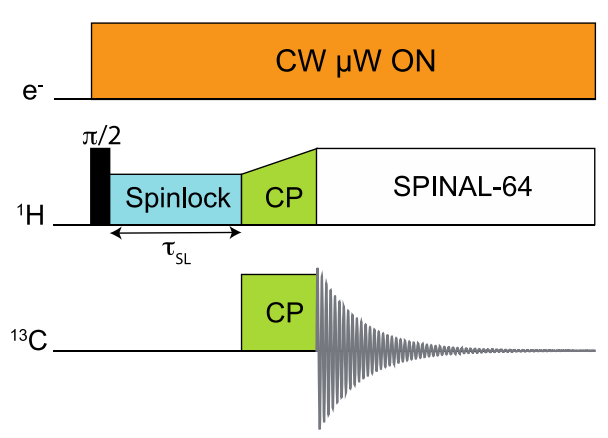

Figure 6. Pulse sequence for recording $T_{1 \rho}$ filtered ${ }^{13} \mathrm{C}$ CPMAS NMR spectra. A spinlock is applied on the ${ }^{1} \mathrm{H}$ channel before the crosspolarization $(\mathrm{CP})$ pulse sequence.

pulse. The nutation frequency of the spinlock pulse was $60 \mathrm{kHz}$, with a duration of $\tau_{\mathrm{sL}}=35 \mathrm{~ms}$; the delay $\tau_{\mathrm{sL}}$ was adjusted by monitoring the intensity of the signal due to the amorphous glycine/water frozen solution in steps of $5 \mathrm{~ms}$ until full disappearance. During the $\tau_{\mathrm{sL}}$ delay, transverse magnetization relaxes in the presence of spin-locking with time constant $T_{1 \rho}$. As amorphous phases have shorter $T_{1 \rho}$ than crystalline phases, signals due to amorphous phases are filtered out of the measured spectrum.

Both ${ }^{13} \mathrm{C}$ CPMAS and $T_{1 \rho}$ filtered ${ }^{13} \mathrm{C}$ CPMAS NMR spectra were recorded with a recycle delay of $30 \mathrm{~s}$ and a $\mathrm{CP}$ contact time of $2 \mathrm{~ms}$. ${ }^{1} \mathrm{H}$ decoupling used the SPINAL decoupling scheme ${ }^{72}$ (pulse length, $4.6 \mu$ s; nutation frequency, $90 \mathrm{kHz}$ ). The ${ }^{13} \mathrm{C}$ CPMAS NMR spectra were recorded with 8 repetitions, while the $T_{1 \rho}$ filtered ${ }^{13} \mathrm{C}$ CPMAS NMR spectra were recorded with 2048 repetitions.

The difference in absolute sensitivity between DNP and standard solid-state NMR experiments was evaluated with two aliquots of the mesoporous silica material impregnated with aqueous glycine solution and left in ambient air for $80 \mathrm{~h}$. After $80 \mathrm{~h}$, the amount of crystallized $\beta$ polymorph was detected by both standard NMR and DNP experiments. The ${ }^{13} \mathrm{C}$ NMR absolute sensitivity was $S=7 \mathrm{~min}^{-1 / 2}$ for DNP and $S=0.45 \mathrm{~min}^{-1 / 2}$ for standard NMR. Thus, DNP yielded 15 times higher ${ }^{13} \mathrm{C}$ NMR sensitivity.

Standard Solid-State NMR. Solid-state NMR spectra without DNP (shown in Figure 5) were recorded on a Bruker 9.4 $\mathrm{T}$ wide-bore magnet (Larmor frequencies: ${ }^{1} \mathrm{H}, 400 \mathrm{MHz} ;{ }^{13} \mathrm{C}, 100 \mathrm{MHz}$ ) operated by AVANCE-III or AVANCE-III HD NMR spectrometers with a
Bruker $4 \mathrm{~mm}$ double-resonance ${ }^{1} \mathrm{H} /\left\{{ }^{29} \mathrm{Si}-{ }^{13} \mathrm{C}\right\}$ MAS probe. The spectra were recorded at room temperature with 128 repetitions, a recycle delay of $4 \mathrm{~s}$, and a CP contact time of $2 \mathrm{~ms}$; the MAS frequency was $10 \mathrm{kHz}$ in all experiments.

\section{ASSOCIATED CONTENT}

\section{SI Supporting Information}

The Supporting Information is available free of charge at https://pubs.acs.org/doi/10.1021/jacs.0c12982.

Figures showing the different ${ }^{13} \mathrm{C}$ CPMAS NMR spectra recorded during the procedure to generate glycine dihydrate, the mass evolution of the sample over time, the build-up curves of the $\beta$ polymorph of glycine, and the observation of adsorbed glycine in mesoporous SBA15 silica material with wall-embedded TEMPO radicals (PDF)

\section{AUTHOR INFORMATION}

\section{Corresponding Authors}

Pierre Thureau - Aix Marseille Univ, CNRS, ICR, 13397

Marseille, France; 이이이.org/0000-0002-9157-256X;

Email: pierre.thureau@univ-amu.fr

Kenneth D. M. Harris - School of Chemistry, Cardiff University, Cardiff, Wales CF10 3AT, U. K.; (1) orcid.org/ 0000-0001-7855-8598; Email: HarrisKDM@cardiff.ac.uk

Giulia Mollica - Aix Marseille Univ, CNRS, ICR, 13397

Marseille, France; 이이이.org/0000-0002-6896-2447;

Email: giulia.mollica@univ-amu.fr

\section{Authors}

Marie Juramy - Aix Marseille Univ, CNRS, ICR, 13397 Marseille, France

Romain Chèvre - Aix Marseille Univ, CNRS, ICR, 13397 Marseille, France

Paolo Cerreia Vioglio - Aix Marseille Univ, CNRS, ICR,

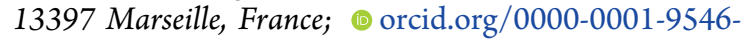
7911

Fabio Ziarelli - Aix Marseille Univ, CNRS, Centrale Marseille, FSCM, 13397 Marseille, France

Eric Besson - Aix Marseille Univ, CNRS, ICR, 13397 Marseille, France

Stéphane Gastaldi - Aix Marseille Univ, CNRS, ICR, 13397 Marseille, France; (1) orcid.org/0000-0003-4363-8322

Stéphane Viel - Aix Marseille Univ, CNRS, ICR, 13397

Marseille, France; Institut Universitaire de France, 75231

Paris, France; @ orcid.org/0000-0003-3338-0559

Complete contact information is available at:

https://pubs.acs.org/10.1021/jacs.0c12982

\section{Notes}

The authors declare no competing financial interest.

\section{ACKNOWLEDGMENTS}

We thank Bruker SAS for access to the solid-state NMR spectrometer used here. This study has received funding from the Excellence Initiative of Aix Marseille UniversityA*Midex, a French "Investissements d'Avenir" program (Grant ANR-11-IDEX-0001-02), from the European Research Council (ERC) under the European Union's Horizon 2020 Research and Innovation Programme (Grant 758498), and from Agence Nationale de la Recherche (Grant ANR-18CE29-007). 


\section{ABBREVIATIONS}

CPMAS, cross-polarization magic angle spinning; DNP, dynamic nuclear polarization.

\section{REFERENCES}

(1) Van Driessche, A. E. S.; Van Gerven, N.; Bomans, P. H. H.; Joosten, R. R. M.; Friedrich, H.; Gil-Carton, D.; Sommerdijk, N. A. J. M.; Sleutel, M. Molecular Nucleation Mechanisms and Control Strategies for Crystal Polymorph Selection. Nature 2018, 556 (7699), 89-94.

(2) Zou, Z.; Habraken, W. J. E. M.; Matveeva, G.; Jensen, A. C. S.; Bertinetti, L.; Hood, M. A.; Sun, C.; Gilbert, P. U. P. A.; Polishchuk, I.; Pokroy, B.; Mahamid, J.; Politi, Y.; Weiner, S.; Werner, P.; Bette, S.; Dinnebier, R.; Kolb, U.; Zolotoyabko, E.; Fratzl, P. A Hydrated Crystalline Calcium Carbonate Phase: Calcium Carbonate Hemihydrate. Science 2019, 363 (6425), 396-400.

(3) Lu, H.; Lutz, H.; Roeters, S. J.; Hood, M. A.; Schäfer, A.; MuñozEspí, R.; Berger, R.; Bonn, M.; Weidner, T. Calcium-Induced Molecular Rearrangement of Peptide Folds Enables Biomineralization of Vaterite Calcium Carbonate. J. Am. Chem. Soc. 2018, 140 (8), 2793-2796.

(4) Ben Shir, I.; Kababya, S.; Zax, D. B.; Schmidt, A. Resilient Intracrystalline Occlusions: A Solid-State NMR View of Local Structure as It Tunes Bulk Lattice Properties. J. Am. Chem. Soc. 2020, 142 (32), 13743-13755.

(5) Schreiber, R. E.; Houben, L.; Wolf, S. G.; Leitus, G.; Lang, Z.-L.; Carbó, J. J.; Poblet, J. M.; Neumann, R. Real-Time Molecular Scale Observation of Crystal Formation. Nat. Chem. 2017, 9 (4), 369-373.

(6) Bernstein, J. Polymorphism in Molecular Crystals; Oxford University Press, 2002; pp 1-401.

(7) Gebauer, D.; Wolf, S. E. Designing Solid Materials from Their Solute State: A Shift in Paradigms toward a Holistic Approach in Functional Materials Chemistry. J. Am. Chem. Soc. 2019, 141 (11), 4490-4504.

(8) Desiraju, G. R. Crystal Engineering: From Molecule to Crystal. J. Am. Chem. Soc. 2013, 135 (27), 9952-9967.

(9) Hamilton, B. D.; Ha, J.-M.; Hillmyer, M. A.; Ward, M. D. Manipulating Crystal Growth and Polymorphism by Confinement in Nanoscale Crystallization Chambers. Acc. Chem. Res. 2012, 45, 414423.

(10) Stephens, C. J.; Kim, Y.-Y.; Evans, S. D.; Meldrum, F. C.; Christenson, H. K. Early Stages of Crystallization of Calcium Carbonate Revealed in Picoliter Droplets. J. Am. Chem. Soc. 2011, 133 (14), 5210-5213.

(11) Sonnenberger, N.; Anders, N.; Golitsyn, Y.; Steinhart, M.; Enke, D.; Saalwächter, K.; Beiner, M. Pharmaceutical Nanocrystals Confined in Porous Host Systems - Interfacial Effects and Amorphous Interphases. Chem. Commun. 2016, 52 (24), 4466-4469.

(12) Meldrum, F. C.; O'Shaughnessy, C. Crystallization in Confinement. Adv. Mater. 2020, 32 (31), 2001068.

(13) Cheng, S.; McKenna, G. B. Nanoconfinement Effects on the Glass Transition and Crystallization Behaviors of Nifedipine. Mol. Pharmaceutics 2019, 16 (2), 856-866.

(14) Jiang, Q.; Ward, M. D. Crystallization under Nanoscale Confinement. Chem. Soc. Rev. 2014, 43, 2066-2079.

(15) Jiang, Q.; Hu, C.; Ward, M. D. Stereochemical Control of Polymorph Transitions in Nanoscale Reactors. J. Am. Chem. Soc. 2013, 135 (6), 2144-2147.

(16) Hamilton, B. D.; Hillmyer, M. A.; Ward, M. D. Glycine Polymorphism in Nanoscale Crystallization Chambers. Cryst. Growth Des. 2008, 8, 3368-3375.

(17) Pouget, E. M.; Bomans, P. H. H.; Goos, J. A. C. M.; Frederik, P. M.; de With, G.; Sommerdijk, N. A. J. M. The Initial Stages of Template-Controlled $\mathrm{CaCO} 3$ Formation Revealed by Cryo-TEM. Science 2009, 323 (5920), 1455-1458.

(18) Aizenberg, J.; Black, A. J.; Whitesides, G. M. Control of Crystal Nucleation by Patterned Self-Assembled Monolayers. Nature 1999, 398 (6727), 495-498.
(19) Travaille, A. M.; Kaptijn, L.; Verwer, P.; Hulsken, B.; Elemans, J. A. A. W.; Nolte, R. J. M.; van Kempen, H. Highly Oriented SelfAssembled Monolayers as Templates for Epitaxial Calcite Growth. J. Am. Chem. Soc. 2003, 125 (38), 11571-11577.

(20) Pichon, B. P.; Bomans, P. H. H.; Frederik, P. M.; Sommerdijk, N. A. J. M. A Quasi-Time-Resolved CryoTEM Study of the Nucleation of $\mathrm{CaCO}_{3}$ under Langmuir Monolayers. J. Am. Chem. Soc. 2008, 130 (12), 4034-4040.

(21) Fischer, E. Synthese von Polypeptiden. XIII. Chloride Der Aminosäuren Und Polypeptide Und Ihre Verwendung Zur Synthese. Ber. Dtsch. Chem. Ges. 1905, 38 (3), 2914-2925.

(22) Iitaka, Y. A New Form of Glycine. Proc. Jpn. Acad. 1954, 30 (2), $109-112$.

(23) Albrecht, G.; Corey, R. B. The Crystal Structure of Glycine. J. Am. Chem. Soc. 1939, 61 (5), 1087-1103.

(24) Xu, W.; Zhu, Q.; Hu, C. The Structure of Glycine Dihydrate: Implications for the Crystallization of Glycine from Solution and Its Structure in Outer Space. Angew. Chem. 2017, 129 (8), 2062-2066.

(25) Cerreia Vioglio, P.; Mollica, G.; Juramy, M.; Hughes, C. E.; Williams, P. A.; Ziarelli, F.; Viel, S.; Thureau, P.; Harris, K. D. M. Insights into the Crystallization and Structural Evolution of Glycine Dihydrate by In Situ Solid-State NMR Spectroscopy. Angew. Chem. Int. Ed. 2018, 57 (22), 6619-6623.

(26) Iitaka, Y. The Crystal Structure of $\beta$-Glycine. Acta Crystallogr. 1960, 13 (1), 35-45.

(27) Iitaka, Y. The Crystal Structure of $\gamma$-Glycine. Acta Crystallogr. 1961, 14 (1), 1-10.

(28) Iitaka, Y. Crystal Structure of $\beta$-Glycine. Nature 1959, 183 (4658), 390-391.

(29) Goryainov, S. V.; Kolesnik, E. N.; Boldyreva, E. V. A Reversible Pressure-Induced Phase Transition in $\beta$-Glycine at 0.76GPa. Phys. $B$ 2005, 357 (3), 340-347.

(30) Tumanov, N. A.; Boldyreva, E. V.; Ahsbahs, H. Structure Solution and Refinement from Powder or Single-Crystal Diffraction Data? Pros and Cons: An Example of the High-Pressure B'Polymorph of Glycine. Powder Diffr. 2008, 23 (4), 307-316.

(31) Dawson, A.; Allan, D. R.; Belmonte, S. A.; Clark, S. J.; David, W. I. F.; McGregor, P. A.; Parsons, S.; Pulham, C. R.; Sawyer, L. Effect of High Pressure on the Crystal Structures of Polymorphs of Glycine. Cryst. Growth Des. 2005, 5 (4), 1415-1427.

(32) Boldyreva, E. V.; Ivashevskaya, S. N.; Sowa, H.; Ahsbahs, H.; Weber, H. P. Effect of Hydrostatic Pressure on the GammaPolymorph of Glycine. 1. A Polymorphic Transition into a New Delta-Form. Z. Kristallogr. 2005, 220 (1), 50-57.

(33) Moggach, S. A.; Marshall, W. G.; Rogers, D. M.; Parsons, S. How Focussing on Hydrogen Bonding Interactions in Amino Acids Can Miss the Bigger Picture: A High-Pressure Neutron Powder Diffraction Study of $\varepsilon$-Glycine. CrystEngComm 2015, 17 (28), 53155328.

(34) Goryainov, S. V.; Boldyreva, E.; Kolesnik, E. N. Raman Observation of a New (Zeta) Polymorph of Glycine? Chem. Phys. Lett. 2006, 419 (4-6), 496-500.

(35) Mali, G. Looking into metal-organic frameworks with solidstate NMR spectroscopy. In Metal Organic Frameworks; Zafar, F., Sharmin, E., Eds.; IntechOpen, 2016; pp 37-60.

(36) Skorupska, E.; Jeziorna, A.; Kazmierski, S.; Potrzebowski, M. J. Recent Progress in Solid-State NMR Studies of Drugs Confined within Drug Delivery Systems. Solid State Nucl. Magn. Reson. 2014, $57-58,2-16$.

(37) Yang, X.; Ong, T.-C.; Michaelis, V. K.; Heng, S.; Griffin, R. G.; Myerson, A. S. Formation of Organic Molecular Nanocrystals under Soft Confinement. CrystEngComm 2015, 17 (31), 6044-6052.

(38) Radhakrishnan, S.; Goossens, P.-J.; Magusin, P. C. M. M.; Sree, S. P.; Detavernier, C.; Breynaert, E.; Martineau, C.; Taulelle, F.; Martens, J. A. In Situ Solid-State ${ }^{13}$ C NMR Observation of Pore Mouth Catalysis in Etherification of $\beta$-Citronellene with Ethanol on Zeolite Beta. J. Am. Chem. Soc. 2016, 138 (8), 2802-2808. 
(39) Hughes, C. E.; Harris, K. D. M. Direct Observation of a Transient Polymorph during Crystallization. Chem. Commun. 2010, 46 (27), 4982-4984.

(40) Hughes, C. E.; Harris, K. D. M. A Technique for In Situ Monitoring of Crystallization from Solution by Solid-State 13C CPMAS NMR Spectroscopy. J. Phys. Chem. A 2008, 112, 6808-6810.

(41) Hughes, C. E.; Williams, P. A.; Harris, K. D. M. "CLASSIC NMR": An In-Situ NMR Strategy for Mapping the Time-Evolution of Crystallization Processes by Combined Liquid-State and Solid-State Measurements. Angew. Chem., Int. Ed. 2014, 53 (34), 8939-8943.

(42) Vioglio, P. C.; Thureau, P.; Juramy, M.; Ziarelli, F.; Viel, S.; Williams, P. A.; Hughes, C. E.; Harris, K. D. M.; Mollica, G. A Strategy for Probing the Evolution of Crystallization Processes by Low-Temperature Solid-State NMR and Dynamic Nuclear Polarization. J. Phys. Chem. Lett. 2019, 10 (7), 1505-1510.

(43) Paruzzo, F. M.; Hofstetter, A.; Musil, F.; De, S.; Ceriotti, M.; Emsley, L. Chemical Shifts in Molecular Solids by Machine Learning. Nat. Commun. 2018, 9 (1), 4501.

(44) Weber, E. M. M.; Kress, T.; Abergel, D.; Sewsurn, S.; Azaïs, T.; Kurzbach, D. Assessing the Onset of Calcium Phosphate Nucleation by Hyperpolarized Real-Time NMR. Anal. Chem. 2020, 92 (11), $7666-7673$.

(45) Xiao, D.; Xu, S.; Brownbill, N. J.; Paul, S.; Chen, L.-H.; Pawsey, S.; Aussenac, F.; Su, B.-L.; Han, X.; Bao, X.; Liu, Z.; Blanc, F. Fast Detection and Structural Identification of Carbocations on Zeolites by Dynamic Nuclear Polarization Enhanced Solid-State NMR. Chem. Sci. 2018, 9 (43), 8184-8193.

(46) Jeon, J.; Yau, W.-M.; Tycko, R. Millisecond Time-Resolved Solid-State NMR Reveals a Two-Stage Molecular Mechanism for Formation of Complexes between Calmodulin and a Target Peptide from Myosin Light Chain Kinase. J. Am. Chem. Soc. 2020, 142, 21220-21232.

(47) Hall, D. A.; Maus, D. C.; Gerfen, G. J.; Inati, S. J.; Becerra, L. R.; Dahlquist, F. W.; Griffin, R. G. Polarization-Enhanced NMR Spectroscopy of Biomolecules in Frozen Solution. Science 1997, 276 (5314), 930-932.

(48) Rossini, A. J.; Zagdoun, A.; Lelli, M.; Lesage, A.; Coperet, C.; Emsley, L. Dynamic Nuclear Polarization Surface Enhanced NMR Spectroscopy. Acc. Chem. Res. 2013, 46 (9), 1942-1951.

(49) Lee, D.; Leroy, C.; Crevant, C.; Bonhomme-Coury, L.; Babonneau, F.; Laurencin, D.; Bonhomme, C.; De Paëpe, G. Interfacial Ca 2+ Environments in Nanocrystalline Apatites Revealed by Dynamic Nuclear Polarization Enhanced 43 Ca NMR Spectroscopy. Nat. Commun. 2017, 8 (1), 14104.

(50) Ni, Q. Z.; Daviso, E.; Can, T. V.; Markhasin, E.; Jawla, S. K.; Swager, T. M.; Temkin, R. J.; Herzfeld, J.; Griffin, R. G. High Frequency Dynamic Nuclear Polarization. Acc. Chem. Res. 2013, 46 (9), 1933-1941.

(51) Song, C.; Hu, K.-N.; Joo, C.-G.; Swager, T. M.; Griffin, R. G. TOTAPOL: A Biradical Polarizing Agent for Dynamic Nuclear Polarization Experiments in Aqueous Media. J. Am. Chem. Soc. 2006, 128 (35), 11385-11390.

(52) Zagdoun, A.; Casano, G.; Ouari, O.; Schwarzwälder, M.; Rossini, A. J.; Aussenac, F.; Yulikov, M.; Jeschke, G.; Copéret, C.; Lesage, A.; Tordo, P.; Emsley, L. Large Molecular Weight Nitroxide Biradicals Providing Efficient Dynamic Nuclear Polarization at Temperatures up to $200 \mathrm{~K}$. J. Am. Chem. Soc. 2013, 135 (34), 12790-12797.

(53) Sauvée, C.; Rosay, M.; Casano, G.; Aussenac, F.; Weber, R. T.; Ouari, O.; Tordo, P. Highly Efficient, Water-Soluble Polarizing Agents for Dynamic Nuclear Polarization at High Frequency. Angew. Chem., Int. Ed. 2013, 52 (41), 10858-10861.

(54) Davey, R. J.; Schroeder, S. L. M.; ter Horst, J. H. Nucleation of Organic Crystals-A Molecular Perspective. Angew. Chem., Int. Ed. 2013, 52 (8), 2166-2179.

(55) Meirzadeh, E.; Dishon, S.; Weissbuch, I.; Ehre, D.; Lahav, M.; Lubomirsky, I. Solvent-Induced Crystal Polymorphism as Studied by Pyroelectric Measurements and Impedance Spectroscopy: Alcohols as
Tailor-Made Inhibitors of $\alpha$-Glycine. Angew. Chem., Int. Ed. 2018, 57 (18), 4965-4969.

(56) Weissbuch, I.; Torbeev, V. Y.; Leiserowitz, L.; Lahav, M. Solvent Effect on Crystal Polymorphism: Why Addition of Methanol or Ethanol to Aqueous Solutions Induces the Precipitation of the Least Stable $\beta$ Form of Glycine. Angew. Chem., Int. Ed. 2005, 44 (21), 3226-3229.

(57) Rossini, A. J.; Zagdoun, A.; Lelli, M.; Canivet, J.; Aguado, S.; Ouari, O.; Tordo, P.; Rosay, M.; Maas, W. E.; Copéret, C.; Farrusseng, D.; Emsley, L.; Lesage, A. Dynamic Nuclear Polarization Enhanced Solid-State NMR Spectroscopy of Functionalized MetalOrganic Frameworks. Angew. Chem., Int. Ed. 2012, 51 (1), 123-127.

(58) Cao, W.; Wang, W. D.; Xu, H.-S.; Sergeyev, I. V.; Struppe, J.; Wang, X.; Mentink-Vigier, F.; Gan, Z.; Xiao, M.-X.; Wang, L.-Y.; Chen, G.-P.; Ding, S.-Y.; Bai, S.; Wang, W. Exploring Applications of Covalent Organic Frameworks: Homogeneous Reticulation of Radicals for Dynamic Nuclear Polarization. J. Am. Chem. Soc. 2018, 140 (22), 6969-6977.

(59) Cavaillès, M.; Bornet, A.; Jaurand, X.; Vuichoud, B.; Baudouin, D.; Baudin, M.; Veyre, L.; Bodenhausen, G.; Dumez, J.-N.; Jannin, S.; Copéret, C.; Thieuleux, C. Tailored Microstructured Hyperpolarizing Matrices for Optimal Magnetic Resonance Imaging. Angew. Chem., Int. Ed. 2018, 57 (25), 7453-7457.

(60) Besson, E.; Ziarelli, F.; Bloch, E.; Gerbaud, G.; Queyroy, S.; Viel, S.; Gastaldi, S. Silica Materials with Wall-Embedded Nitroxides Provide Efficient Polarization Matrices for Dynamic Nuclear Polarization NMR. Chem. Commun. 2016, 52 (32), 5531-5533.

(61) Silverio, D. L.; van Kalkeren, H. A.; Ong, T.-C.; Baudin, M.; Yulikov, M.; Veyre, L.; Berruyer, P.; Chaudhari, S.; Gajan, D.; Baudouin, D.; Cavaillès, M.; Vuichoud, B.; Bornet, A.; Jeschke, G.; Bodenhausen, G.; Lesage, A.; Emsley, L.; Jannin, S.; Thieuleux, C.; Copéret, C. Tailored Polarizing Hybrid Solids with Nitroxide Radicals Localized in Mesostructured Silica Walls. Helv. Chim. Acta 2017, 100 (6), e1700101.

(62) Yarava, J. R.; Chaudhari, S. R.; Rossini, A. J.; Lesage, A.; Emsley, L. Solvent Suppression in DNP Enhanced Solid State NMR. J. Magn. Reson. 2017, 277, 149-153.

(63) Folliet, N.; Gervais, C.; Costa, D.; Laurent, G.; Babonneau, F.; Stievano, L.; Lambert, J.-F.; Tielens, F. A Molecular Picture of the Adsorption of Glycine in Mesoporous Silica through NMR Experiments Combined with DFT-D Calculations. J. Phys. Chem. C 2013, 117, 4104-4114.

(64) Ben Shir, I.; Kababya, S.; Schmidt, A. Binding Specificity of Amino Acids to Amorphous Silica Surfaces: Solid-State NMR of Glycine on SBA-15. J. Phys. Chem. C 2012, 116, 9691-9702.

(65) Piveteau, L.; Ong, T.-C.; Rossini, A. J.; Emsley, L.; Copéret, C.; Kovalenko, M. V. Structure of Colloidal Quantum Dots from Dynamic Nuclear Polarization Surface Enhanced NMR Spectroscopy. J. Am. Chem. Soc. 2015, 137 (43), 13964-13971.

(66) Zhang, K.; Fellah, N.; López-Mejías, V.; Ward, M. D. Polymorphic Phase Transformation Pathways under Nanoconfinement: Flufenamic Acid. Cryst. Growth Des. 2020, 20 (11), 70987103.

(67) Nabokoff, P.; Gastaldi, S.; Besson, E. Probing the Efficiency of Thermal and Photochemical Bond Homolysis in Functionalized Nanostructured SBA-15 Silicas. Microporous Mesoporous Mater. 2021, $311,110674$.

(68) Seidell, A. Solubilities of Inorganic and Organic Compounds, 2nd ed.; D. Van Nostrand Co.: New York, 1919; pp 306-307.

(69) Park, K.; Evans, J. M. B.; Myerson, A. S. Determination of Solubility of Polymorphs Using Differential Scanning Calorimetry. Cryst. Growth Des. 2003, 3 (6), 991-995.

(70) Yang, X.; Wang, X.; Ching, C. B. Solubility of Form $\alpha$ and Form $\gamma$ of Glycine in Aqueous Solutions. J. Chem. Eng. Data 2008, 53 (5), 1133-1137.

(71) Stevenson, J. D.; Wolynes, P. G. The Ultimate Fate of Supercooled Liquids. J. Phys. Chem. A 2011, 115 (16), 3713-3719. 
(72) Fung, B. M.; Khitrin, A. K.; Ermolaev, K. An Improved Broadband Decoupling Sequence for Liquid Crystals and Solids. J. Magn. Reson. 2000, 142 (1), 97-101. 